\title{
Comentario normativo sobre el uso del superlativo valientísimo y del indefinido singular en la expresión cualquiera que sean por parte de estudiantes de nivel avanzado de ELE
}

\author{
María Pilar Sanchis Cerdán \\ Università degli Studi di Trieste \\ msanchis@units.it
}

Resumen: En este artículo tratamos de exponer, recurriendo principalmente a obras normativas y a bases de datos, la dificultad de señalar como incorrectas expresiones empleadas por estudiantes de Español como Lengua Extranjera en un nivel C1. Analizamos para ello dos ejemplos que pueden ilustrar bien esta cuestión: el uso de la forma valientísimo (frente a valentísimo) como superlativo del adjetivo valiente, y el empleo del pronombre indefinido singular (frente al plural cualesquiera) en la fórmula cualquiera que sean. Pretendemos despertar una reflexión en el lector, posible docente de Lengua Española, y ayudarle, quizás, a replantearse explicaciones gramaticales en materia de norma.

Palabras clave: gramática normativa, adjetivo superlativo valentísimo/valientísimo, pronombre indefinido cualquiera/cualesquiera, ELE. 


\title{
Normative commentary about the superlative form valientisimo and the singular indefinite pronoun cualquiera in cualquiera que sean both used by students of Spanish as a Foreign Language in an upper level
}

\begin{abstract}
We will try to expose in this essay, mainly by means of normative works and data bases, the difficulty of striking out incorrect expressions used by students of Spanish as a Foreign Language in a C1 level. For this purpose we will analyze two examples which may illustrate this question well: the use of valientísimo (as opposed to valentísimo) as the superlative form of the adjective valiente, and the use of the singular indefinite pronoun cualquiera (as opposed to the plural form cualesquiera) in the expression cualquiera que sean. We intend to awaken a reflection in the reader, possible teacher of Spanish Language, and perhaps help him or her to rethink normative grammar explanations.
\end{abstract}

Keywords: Normative grammar, superlative adjective valentísimo/valientísimo, indefinite pronoun cualquiera/cualesquiera, Spanish as a Foreign Language.

Recibido el 09/10/2017

Aceptado el 11/06/2018 


\section{Introducción}

La lengua es un don que no debe descuidarse; para ayudarnos a utilizarla con esmero existen obras creadoras de norma que nos guían en este sentido. A ellas podemos acudir especialmente cuando nos surgen dudas sobre el empleo adecuado o no de ciertas expresiones (así lo hemos hecho en este ejercicio: las obras consultadas aparecen en el apartado de Referencias bibliográficas ${ }^{1}$ ). No obstante, cabe señalar que la lengua viva está siempre «en ebullición», y, precisamente por ello, consideramos que deben evitarse dictámenes categóricos a la hora de evaluar su uso; ya que está demostrado que ciertos usos considerados inapropiados en un determinado periodo han ido progresivamente aumentando su frecuencia de aparición, llegando a ser aceptados, en un periodo posterior, por la mayoría de hablantes, incluso en registros cultos - clara muestra de esto es, por ejemplo, la elisión de /d/ intervocálica en las formas de participio de la primera conjugación-. En este sentido, bases de datos como las de la Real Academia Española ${ }^{2}$ o buscadores como Google reflejan cuál es el uso efectivo que hacen los hablantes de una lengua y pueden ayudarnos, por tanto, en nuestra labor de docentes.

A pesar de esto, en nuestra experiencia en el ámbito de la enseñanza de Español como Lengua Extranjera ${ }^{3}$, hemos podido comprobar que a menudo se pasa por alto este aspecto y se corrigen «fallos» en los estudiantes, a nuestro parecer, de manera equivocada. La causa de esto radica en que los profesores - especialmente cuando la docencia se ejerce en países de habla no hispana- tienen en cuenta el uso común y tradicionalmente considerado como correcto hasta el momento de la expresión utilizada por el alumno, sin detenerse a reflexionar sobre si la forma en cuestión cuenta actualmente con aceptación en la comunidad de hablantes y sin analizar si esta está contemplada en las obras académicas, incluso.

Siguiendo estas apreciaciones, y haciendo uso tanto de obras normativas como de ejemplos obtenidos a través de los recursos mencionados para poder exponer con rigor nuestro parecer a este respecto ( $y$ verificar si una forma determinada puede considerarse correcta o no, y hasta qué punto), hemos decidido analizar dos ejemplos empleados por estudiantes que poseen un nivel $\mathrm{C} 1^{4} \mathrm{de}$ español: valientísimo y cualquiera que sean. La elección de examinar fallos en el nivel $\mathrm{C} 1$ se debe, principalmente, a que es en este nivel donde aparecen usos que, pese a que puedan considerarse posiblemente como no normativos, requieren

1. Se observará que, aunque parte de estas obras no son académicas, son también fundamentales en el análisis del uso del español.

2. En adelante, RAE.

3. En adelante, ELE.

4. Según el MCER (Marco Común Europeo de Referencia para las lenguas). 
una importante revisión por parte del docente. Asimismo, la elección obedece a criterios académicos, ya que, con frecuencia, es en los niveles superiores de enseñanza donde el profesor encuentra mayores escollos.

\section{El error en los estudiantes a partir del nivel $\mathrm{C}^{5}$}

El error es utilizado como herramienta fundamental en la enseñanza de ELE. Sin embargo, si es cierto que de los errores se aprende, también lo es que un error corregido como tal cuando no lo es, al menos en sentido estricto, puede inducir a confusión en el aprendiente. En los niveles iniciales del aprendizaje el estudiante no suele plantearse si los errores que comete lo son efectivamente; no suele verificar las correcciones o precisiones que el docente le hace. No obstante, con frecuencia, una vez adquirido un cierto dominio de la lengua meta (principalmente a partir de un nivel B1), el alumno comienza a cuestionarse por qué ha cometido ese error y si las explicaciones que el profesor le ha dado son convincentes. Probablemente, intentará contrastarlas en los manuales que tiene a disposición - labor que, indudablemente, el docente deberá haber llevado a cabo con anterioridad, con el fin de que ambas informaciones coincidan-. Por otra parte, debemos considerar también que el estudiante de una lengua extranjera suele prestar gran atención a las estructuras empleadas por sus hablantes (sin posibilidad de discernir lo que es normativo de lo que no lo es), por lo que numerosas veces, al ser corregidos, recurrirán a este aspecto para justificar su error. Todo esto ocurre especialmente en alumnos que cuentan ya con un nivel $\mathrm{C} 1$, dado que el estudiante que posee este nivel, en su afán por aprender y contar con un dominio total (o casi) del español, llega a tener conocimientos muy profundos de la lengua: pensemos que muchos de estos estudiantes podrían pasar por hispanohablantes, a no ser por errores como los que presentamos en este trabajo ${ }^{6}$; de ahí la dificultad de identificar como agramaticales o no normativas ciertas expresiones empleadas por ellos, sin cerciorarse de que, efectivamente, lo son stricto sensu.

En efecto, este tipo de alumnos utiliza expresiones complejas que los aprendientes de niveles inferiores desconocen o no se atreven a usar — lo que Schachter (1974) definió como estrategia de la inbibición ${ }^{7}$-; y, cuando lo hacen, suele

\footnotetext{
5. Los datos que exponemos han sido deducidos de nuestra propia experiencia a lo largo de más de diez años con estudiantes universitarios y de academias de lenguas procedentes de Italia, Alemania, República Checa, Eslovenia, Polonia, Inglaterra y Estados Unidos. Sería, quizás, interesante realizar un estudio sistemático, más extenso y detallado, de tipos de errores en este nivel, por alumnos cuyas lenguas maternas procedan también de familias diferentes.

6. Cabe considerar que hay hablantes de español que no poseen un nivel C2.

7. Esto es: el alumno de una L2 tiende a evitar el empleo de formas con las que no está familiarizado por miedo a incurrir en error.
} 
ser de manera correcta ${ }^{8}$, al haberse cerciorado a priori de cuál era la forma normativa. De hecho, los estudiantes que cuentan ya con un nivel C1 muestran una gran seguridad a la hora de emplear el lenguaje, en ocasiones, incurriendo por este motivo en error: por tendencia a la regularización, por ultracorrección, por fosilización, por imitación (método ampliamente descrito por Ellis en su obra, 1985). A este respecto, debemos tener en cuenta también que el input (en términos de VanPattern, 2002) no siempre llega a través del aula de ELE, sino que los alumnos escuchan también a otros usuarios del español, que pueden estar utilizando fórmulas no normativas.

Así pues, en un caso como el del superlativo valientísismo, no es de extrañar que los estudiantes utilicen la forma diptongada, ya que tienden a construir ( $y$ esto ocurre en cualquier nivel) formas regulares. Sin embargo, el hecho de que este error particular aparezca en un nivel C1 se debe a que el alumno de niveles inferiores evita el empleo de los superlativos absolutos sintéticos — salvo en el caso de aquellas formas empleadas comúnmente (malisimo, guapísimo, grandísimo...) - , utilizando con preferencia formas analíticas como muy valiente, muy alto, muy pesado, muy fuerte, etc. Cuando finalmente se decide a emplear la forma sintética, lo hace usando una forma regular, que, en la mayoría de los casos, suele ser correcta. El uso de la expresión cualquiera que sean ${ }^{9}$ presenta otro ejemplo ilustrativo. En este caso los alumnos parecen ${ }^{10}$ optar por la forma que les es más familiar, dado que la forma plural cualesquiera es, como veremos, un indefinido poco frecuente entre los usuarios, sobre todo en el lenguaje oral, y lo desconocen o no lo recuerdan por este motivo. Además, debido a su naturaleza de compuesto de cual y quiera los alumnos a menudo identifican, por otra parte, el pronombre cual como sujeto de quiera, por lo que les parece incluso erróneo utilizar el plural cuales como parte del indefinido compuesto, llegando a veces a formar, cuando se les señala el error, el indefinido ultracorregido cualesquieran. Otras veces, construyen la forma errada cualesquieras, al imitar el primer segmento del compuesto (cuales-) en el segundo (-quieras). En cualquiera de los casos, como se ha dicho, no basta con señalar el error y plantearse por qué el alumno lo comete, sino que es necesario asegurarse de que la forma específica puede ser calificada como agramatical y/o no normativa (como, en efecto, sucedería con cualesquieran o cuales-

8. Es la conocida teoría del aprendizaje en forma de U, en este caso según el modelo de Kellerman (1983): los estudiantes de una L2 presentarían más aciertos en un nivel intermedio que en un nivel superior en determinados contextos.

9. Hemos optado por analizar el indefinido en esta expresión, puesto que su índice de aparición (según muestran los bancos de datos de la RAE y el buscador Google) es mayor dentro de esta estructura - además, se emplea, en cualquier caso, más como pronombre que como adjetivo-.

10. Tanto estas averiguaciones como las referidas al superlativo valentísimo se han hecho preguntando directamente el porqué de su elección a los estudiantes que cometían los fallos. 
quieras $\left.^{11}\right)$, ya que en caso contrario se debería matizar cuáles son los contextos en que se puede (o se suele, a pesar de no ser normativa) emplear.

A continuación, presentamos un análisis pormenorizado de valientísimo y de cualquiera que sean en el que se expondrá qué apreciaciones se recogen en las obras de referencia a este respecto ${ }^{12}$, y cuál es el uso que reflejan las bases de datos de la RAE y el buscador Google.

\section{El superlativo valentísimo valientísimo}

En cuanto al superlativo de valiente, es interesante señalar que en el Diccionario de la lengua española ${ }^{13}$ (2014) de la RAE, en la entrada correspondiente a este término, se señala que este adjetivo consta de un superlativo irregular valentísimo; y contempla, asimismo, una entrada para esta forma, contrariamente a lo que suele suceder en los diccionarios - en efecto, no se recoge valientísimo en una entrada aparte, sino como superlativo regular en la entrada valiente-. Esto ocurre con otros adjetivos superlativos irregulares o que pueden presentar dificultad ${ }^{14}$ como fortísimo, bonísimo, sacratísimo, etc. De hecho, en la Nueva gramática de la lengua española ${ }^{15}$ (2009: $\left.\$ 7.4 b, 523\right)$ se explica que «el DRAE solo suele recoger los que presentan particularidades morfofonológicas, aplicando el mismo criterio que se tiene en cuenta con los derivados en -ito y otros sufijos apreciativos». Este es el motivo por el cual no aparecen, pues, adjetivos comunes como durísimo, larguísimo, sencillísimo, etc.

En el Diccionario panhispánico de dudas ${ }^{16}$ (2005: véase valiente) se amplía la información al señalarse que valiente «tiene dos superlativos válidos: valentísimo, que conserva la raíz del adjetivo latino y es mayoritario en el uso culto, y valientísimo, formado sobre valiente (->-1́simo, $\underline{3}$ ): "En el último toro estuvo valentísimo" (Tapia Toreo [Esp. 1992]); “Continuó sentada valientísima y muy segura de sí

\footnotetext{
11. La forma cualesquieran no se contempla en ninguna de las obras examinadas en materia de norma, y cuenta con un índice de aparición muy bajo en el buscador Google (4620 veces) y en las bases de datos de la RAE (aparece solamente una vez en el CREA). Sí se recoge, en cambio, cualesquieras como forma no normativa en el Diccionario panhispánico de dudas; aparece una vez en el CORDE y 10300 en Google.

12. Aunque hemos consultado también la Ortografía de la lengua española (2010), no aporta datos pertinentes: en el caso de cualquiera/cualesquiera aparece solo una pequeña nota adicional que se limita a señalar su condición de relativo inespecífico o indefinido; por su parte, en cuanto al superlativo, encontramos solo información sobre el sufijo -ísimo, pero, de nuevo, sin relevancia para este estudio. Además, se ha consultado el Diccionario esencial de la lengua española (2006), que no ha aportado ningún dato atinente.

13. En adelante, DLE.

14. Por ejemplo, no aparecen, aunque contienen pequeñas irregularidades, superlativos como mayorcísimo, seguramente, dado que su uso generalizado hace que no planteen problemas.

15. En adelante, NGLE.

16. En adelante, DPD.
} 
misma” (Bryce Mundo [Perú 1970])». Nos remite, además, al apartado 3 de la entrada -ísimo, donde se explica lo siguiente:

3. Muchos adjetivos que tienen en su raíz los diptongos ie o ue presentan en el superlativo formas sin diptongar que conservan la raíz del adjetivo latino correspondiente, como ocurre en certísimo, fortísimo, novísimo o ternísimo. En la mayoría de los casos, estas formas alternan en el uso con otras que incorporan la raíz española del adjetivo, como ciertísimo, fuertísimo, nuevísimo o tiernísimo, igualmente válidas y, por lo general, más coloquiales; en algún caso, la forma con diptongo carece de aceptación en el habla culta de algunas zonas, pero es usada con normalidad en otras, como ocurre con calientísimo, forma comúnmente usada en algunos países de América, pero ajena a la norma culta en otras zonas del ámbito hispánico.

En la NGLE (2009: $\$ 7.4$ e, 524) se concuerda básicamente con lo dicho. Se explica que «se perciben más alternancias de diptongación en los derivados en -ísimo/-ísima que en los que se obtienen con otros sufijos. Aunque en la mayoría de los casos predominan las variantes con diptongación en la lengua actual, se observan alternancias». Junto a valentísimo valientísimo, indica otros ejemplos como bonísimo buenísimo, fortísimo fuertísimo, calentísimo calientísimo, etc. A pesar de que no indica una mayor corrección de uno u otro, más adelante señala (2009: $§ 7.4 f, 514-525)$ que «los factores que regulan la distribución de esas formas son variables. [...] Se suelen considerar populares o conversacionales las formas ciertísimo, fuertísimo o valientísimo, mientras que ardentísimo, bonísimo y ferventísimo se sienten muy cultas».

En el Esbozo de una nueva gramática de la lengua española ${ }^{17}$ (1973: 197) se señalaba en su momento ${ }^{18}$ esto:

El morfema -ísimo es esdrújulo y, por consiguiente, el adjetivo pierde su acentuación. Como consecuencia de ello y de la ley fonológica española de alternancias vocálicas, las sílabas acentuadas del adjetivo en las que hay diptongo -ie- [...] procedente [...] de sílaba acentuada latina con -ae-o -e-breve [... en el superlativo aparecen $[\ldots]$ con $-e-[\ldots]$ inacentuada $[s]$.

Esta obra presentaba ejemplos como los ya mencionados bonísimo buenísimo, certísimo $\sim$ certísimo, fortísimo $\sim$ fuertísimo, novísimo $\sim$ nuevísimo, ternísimo $\sim$ tiernísimo, y otros como destrísimo $\sim$ diestrísimo y grosísimo $\sim$ gruesísimo. De hecho, se explicaba que «el uso tiende a introducir el diptongo en el superlativo. Aquí también se dan algunas formas dobles, una coloquial y popular dipton-

17. En adelante, Esbozo.

18. Tengamos presente que el Esbozo (1973) cuenta con más de 40 años desde su edición. 
gada, otra culta y más literal sin diptongar». Sin embargo, se aclaraba que este "principio de alternancia vocálica no presenta tanta regularidad en la formación de los superlativos como en la derivación, y la conservación del diptongo es regular fuera de los casos anteriores». Además, se especificaba (1973: 198) que no diptongaban los superlativos de los adjetivos ardiente, caliente y valiente: ardentísimo, calentísimo y valentísimo. Estas consideraciones coinciden con las de Seco de 1998 (véase valiente), que añade una entrada explícita para valiente en la que destaca como único superlativo valentísimo - aunque expone que hay casos en los que coexisten «la forma latinizante y la moderna o popular, que gana terreno»-; pero no exactamente con las de 2011, donde acoge el uso «coloquial y probablemente más usual» de valientísimo.

En el Diccionario de uso del español (2007) de María Moliner existen entradas específicas para valientísimo (que remite a valentísimo) y valentísimo. En esta última se señala que, aunque este es el superlativo correcto de valiente, se emplea también valientísimo; sin embargo, lo más interesante es que añade «uno y otro, poco usados».

Si contrastamos lo expuesto hasta ahora con los resultados del Nuevo tesoro lexicográfico de la lengua española ${ }^{19}$, observamos que se recoge solo valentísimo como superlativo, pero no aporta nada nuevo a nuestro análisis, puesto que tampoco el DLE (2014) recoge valientísimo como entrada. Quizás sean más reveladores los datos obtenidos en los bancos de la RAE: en el CORDE aparecen 100 casos (en 60 documentos) de valentísimo frente a 6 casos de valientísimo (en 5 documentos); en el CREA, 9 frente a 3; mientras que en el CORPES XXI encontramos 3 ejemplos de valentísimo frente a 1 de valientísimo. Los resultados mostrarían una frecuencia de aparición mayor de valentísimo respecto a valientísimo, lo que nos llevaría a interpretar que valentísimo fue posiblemente en un principio el superlativo más común y, por ello, apropiado; pese a ello, se muestra un uso poco extendido (y quizás en disminución) de sendas formas, hecho que vendría a corroborar lo expuesto en el diccionario de María Moliner. Reveladores son también, en este sentido, los resultados obtenidos en Googleः valentísimo aparece en 13300 ejemplos, frente a los 1630 de valientísimo, lo que indicaría que este último viene a ser utilizado en aproximadamente un $10 \%$ de los casos; sin embargo, de nuevo, cabe considerar que ambos cuentan con un bajo índice de aparición. ${ }^{20}$

19. En adelante, NTLLE.

20. Hemos realizado también la búsqueda diferenciando entre páginas en España y en español, pero los resultados obtenidos son paralelos. 


\section{El indefinido cualquiera en la expresión cualquiera}

\section{que sean}

En el caso del pronombre hemos observado que todas las obras académicas hacen hincapié en que la forma plural del indefinido cualquiera es cualesquiera. En el DLE (2014: véase cualquiera y cualesquiera) aparece una entrada diferente para cada una de las formas; en la entrada para la voz en singular se explica, además, que su plural es cualesquiera. El hecho de que se señale, por otra parte, su naturaleza de compuesto de cual y quiera nos hace reflexionar sobre el carácter invariable que sí adquiere la parte verbal.

En el DPD (2005: véase cualquiera, \$3) se expone:

[E]l plural del adjetivo y del pronombre cualquiera es cualesquiera (no cualesquieras) [...]. A menudo se utiliza erróneamente la forma del singular para el plural: "No se debe, cualquiera que sean las circunstancias, admitir que se denigre el nivel del debate” (DYucatán [Méx.] 12.9.96). Aún más inadmisible resulta el empleo de la forma del plural para el singular: "En nuestro país la tortura o cualesquiera otro acto vejatorio están probibidos" (Dedom [R. Dom.] 19.12.96)».

La NGLE (2009: §19.4c, 1392) concuerda con esta directriz, si bien de modo menos tajante:

El plural de cualquiera es cualesquiera, forma que corresponde a los registros formales: Se puede practicar yoga cualesquiera que sean las creencias religiosas del practicante (Calle Capilla, Yoga). Aunque es un uso que se recomienda evitar, se registran esporádicamente casos en los que el singular cualquier ocupa el lugar de cualesquiera ante el indefinido otros [...].

Se recoge (2009: $\$ 20.4 b, 1467)$ también el empleo de la fórmula «cualquiera $(q u e)^{21}$ sea + grupo nominal», aunque sin referencia al plural, y en $§ 22.12 \mathrm{~g}(2009$ : 1630) se explica:

[L]os relativos inespecíficos cualquiera y quienquiera presentan flexión de número, que se manifiesta en el primer miembro del compuesto: cualesquiera, quienesquiera. El segundo miembro es invariable. Estas variantes en plural se emplean menos que las correspondientes singulares, y suelen estar circunscritas, además, a los registros formales. [... Es frecuente que el singular reemplace al plural en muchos [...] contextos [cualquier otro en lugar de cualesquiera otros] [...] $\sin$ cambio apreciable en la interpretación. No se considera correcta, por el contra-

21. Contempla la ausencia de la partícula que, opción no aceptada en el DPD (2005) y descrita como «no normal» por Seco en 1998 — aunque en 2011 señala que «es posible, pero no frecuente, la supresión del que»-. 
rio, la variante con discordancia de número cualquiera que sean las circunstancias o en cualquiera circunstancias.

En el Esbozo (1973: 231) se hacía una pequeña alusión a este indefinido en línea con lo expuesto hasta aquí:

El plural de cualquiera y cualquier es cualesquiera y cualesquier, enteramente limitado a la lengua escrita. Pero el uso de este plural con valor singular se halla, en cambio, muy extendido en el habla vulgar de España y América. La lengua literaria que no persiga como fin especial el reproducir usos populares y vernáculos debe evitarlo, así como el uso contrario del singular por el plural.

Es interesante destacar cómo se subrayaba en esta obra que la fórmula plural estaba limitada a la lengua escrita, hecho que confirmaba ya su carácter formal.

Por otro lado, Seco (1998 y 2011: véase cualquiera) en el punto 3 de la entrada cualquiera explica que:

El plural de cualquiera, adjetivo o pronombre, es cualesquiera: cualesquiera que sean las causas [...]. En la lengua hablada, y también en la escrita descuidada, es frecuente usar para el plural la misma forma de singular: «Cualquiera que fueran los bechos [...]». Inversamente, por ultracorrección, incurren algunos en el uso de plural por singular: "Tenemos que aspirar a la supresión de cualesquiera forma de alineación» [... . Este uso es también vulgar y está muy extendido en Hispanoamérica.

Observemos que, además de su aparición en el habla, destaca el uso de la forma singular en la lengua «escrita descuidada». La forma aparece también en el Diccionario del español actual (Seco et alii, 1999 y 2011: véase cualesquier y cualquier), donde se señala, nuevamente, que el plural es cualesquiera, aunque se especifica también que «en el nivel col[oquial] se usa [...] la misma forma del $\mathrm{s}$ [in]g[ular]; y, por el contrario, existe un uso semiculto de cualesquier y cualesquiera para el s[in]g[ular]». Sorprende que en esta ocasión se describa el uso de cualesquier para el singular como «semiculto». Aparece, además, un ejemplo de la expresión cualesquiera que sean, frente a dos con cualquiera que sean. Por otra parte, esta obra acoge, como «vulgar», también la forma cualisquiera.

En el Diccionario de uso del español (Moliner, 2007: véase cualesquier y cualquier) se indica que el plural de la forma cualquiera es cualesquiera, "que se usa poco». Así lo indica también Martínez («muy poco») en la Gramática descriptiva de la lengua española (1999: 2734).

En el NTLLE se recoge, asimismo, cualesquiera como plural de cualquiera, no obstante, no se añade ninguna anotación normativa al respecto. Por otra parte, hemos introducido las expresiones cualquiera que sean y cualesquiera que sean en 
los bancos de datos de la RAE y en el buscador de Google: en el primer caso, tanto en el CORDE como en el CREA y en el CORPES XXI, aparece un uso mayoritario de la fórmula con el indefinido en plural (respectivamente: 197 ejemplos con el plural frente a 23; 98 frente a $17^{22} ; 59$ frente a 4). Más interesantes son (por el número de ejemplos obtenidos) los resultados de Google, que muestran una abrumadora preferencia por el uso de la expresión (aparentemente incorrecta) cualquiera que sean - se han observado también numerosos casos incluso en el lenguaje culto-: la búsqueda por «páginas en español» refleja 9120000 resultados frente a 379000 de cualesquiera que sean; y 327000 frente a 126000 en las "páginas en España». ${ }^{23}$ Estos datos son relevantes porque muestran que, respecto a la forma singular, el plural aparece solo en un 39\% y en un $4 \%$ de los casos, respectivamente. Se observa, pues, que en nuestro país el empleo de cualquiera en la estructura analizada está más generalizado que el del pronombre, supuestamente apropiado, cualesquiera; los resultados muestran, además, que el uso de cualesquiera en esta expresión es mucho menor fuera de España. Esto confirmaría que el empleo del singular cualquiera para el plural está ampliamente extendido (mucho más generalizado que el del superlativo valientísimo, por otro lado); lo cual, a su vez, llevaría a replantear si, efectivamente, es adecuado tachar de incorrecta su utilización, a pesar de que, como se ha visto, la mayoría de obras desaconseja su uso.

\section{Conclusiones}

A nuestro juicio, consideraciones como las realizadas hasta aquí deben constituir parte esencial en la enseñanza de ELE; tengamos presente que el empleo de las fórmulas vistas plantea problemas e incertidumbre incluso en hablantes cuya lengua materna es el español, por lo que no es de extrañar que los propios alumnos cometan «fallos» al utilizarlas. Opinamos que el docente debe contribuir a evitar tal confusión, haciendo las aclaraciones oportunas con el fin de que el aprendiente con un nivel C1 (en este caso) pueda seguir ganando conocimiento también para adquirir, de esta manera, un nivel C 2 en la lengua meta, que es lo que se pretende en el aula. En el caso particular de las expresiones valientísimo y cualquiera que sean, $y$ aunque hemos podido comprobar que las observaciones expuestas en las obras normativas son, salvo algunos incisos que expondremos, afines, se ha podido ver que no basta con indicar que son fórmulas no normativas, sino que,

22. Un dato interesante es, quizás, que la mayoría de usos «incorrectos» han sido extraídos de ejemplos de prensa.

23. Al introducir solamente el indefinido aparece también una diferencia abismal ( 92700000 frente a 5940000, y 63600000 frente a 6110000), señal del empleo reducido del plural y de su progresivo desvanecimiento, probablemente. 
a nuestro juicio, sería pertinente añadir comentarios como los que sintetizamos a continuación.

Sobre la corrección del superlativo valientísimo (y de sus variantes valientísima, valientísimos, valientísimas), se señala como más adecuado el uso de valentísimo en contextos formales, y así debemos manifestarlo en el aula de ELE; si bien habría que indicar que los datos obtenidos en las bases y en el buscador avalan la precisión hecha en el diccionario de María Moliner, donde se apuntaba que, tanto este superlativo como la forma regular, son términos poco usados. Por otra parte, podríamos añadir a estas consideraciones que los hablantes parecen oscilar entre una y otra forma, quizás porque, como se exponía en el Esbozo, el uso tiende a introducir el diptongo en el superlativo en el habla coloquial. Por ello, aunque es mayor el porcentaje de aparición de valentísimo, consideramos que es arriesgado tildar de incorrecta la forma regular, cuyo empleo —en proporción con la variante formal - es considerable (la búsqueda en Google mostraba un $12 \%$ de casos). Quizás, más bien, sería oportuno señalar que ambas parecen ser formas en decadencia, como demuestra también la disminución en la aparición de sendos ejemplos en las bases de la RAE.

En cuanto al uso del indefinido singular cualquiera en lugar del plural cualesquiera en la expresión cualquiera que sean (aunque no solo en ella), según las obras consultadas, deberíamos explicar en el aula que quizás deba seguir relegándose a contextos coloquiales por el momento. No obstante, como evidencian los ejemplos extraídos de los recursos analizados (fundamentalmente los resultados de Google), cabe destacar que existe una fuerte aceptación por parte de los hablantes de la forma cualquiera, que llega a utilizarse más que la variante propiamente normativa, por lo que se debería aclarar que, a pesar de ser considerada como coloquial, cualquiera que sean es una fórmula en progreso. Además, se podría reflexionar, principalmente por la poca frecuencia con la que se usa en general el término cualesquiera, y debido a su naturaleza de compuesto de cual(es) y quiera (cuya parte verbal tiene carácter invariable), sobre el posible hecho de que en un futuro la forma cual-adquiriese invariabilidad — algo que sucede ya con el sustantivo cualquiera, cuyo plural es cualquieras - y se aceptase con normalidad también en registros formales.

En fin, el estudiante es un individuo que debe aprender; además, especialmente en niveles avanzados de ELE, no solo quiere, sino que debe conocer el porqué de las correcciones a su producción lingüística. En el presente trabajo hemos pretendido demostrar la dificultad que supone corregir el uso de la lengua, sobre todo en estos niveles. Al inicio de nuestra carrera profesional a menudo señalábamos expresiones utilizadas por nuestros alumnos como incorrectas; sin 
embargo, gracias al estudio periódico de las obras normativas, a su consulta, y a la confrontación de sus recomendaciones con los datos que aportan las bases de datos y el buscador analizados, así como con la observación del uso real que los usuarios del español hacen de estructuras como las presentadas aquí, nos resulta ahora ilógico indicar como erróneas expresiones que parecen ser empleadas comúnmente por los hablantes. En el caso que nos ocupa, y precisamente por los motivos expuestos hasta aquí, creemos que es necesario «corregir» aportando matices a la corrección. Personalmente, no indicamos que expresiones como cualquiera que sean son incorrectas, ni utilizamos fórmulas del tipo «es erróneo» para usos como el de valientísimo-; más bien, es necesario (y esto es sabido) hablar siempre de casos «no normativos» ${ }^{24}$, exponiendo en la clase de ELE, especialmente en niveles avanzados de aprendizaje, las precisiones pertinentes de manera similar a cuanto se ha hecho en este ejercicio. La labor del docente debe consistir en hacer partícipe al aprendiente de tales apreciaciones; especialmente porque, sobre todo en el nivel C1, estas son fundamentales para que el estudiante consiga alcanzar un nivel superior. Demostrarlo y aportar un dato más a la investigación académica en este ámbito es lo que nos ha llevado a analizar estos dos ejemplos.

\section{Referencias bibliográficas}

Ellis, R. (1985). Understanding Second Language Adquisition. Oxford: Oxford University Press.

Google+[https;//www+google.es/?gws_rd=ssl; consulta: 11.07.17].

Kellerman, E. (1983). «If at first you do succeed». En* S. Gass y C. Madden (eds.). Input in Second Language Adquisition. Rowley, Massachusetts. Newbury House: 345-354.

Martínez, J. A. (1999). «La concordancia»+ En* I. Bosque y V. Demonte (eds*). Gramática descriptiva de la lengua española. Madrid. Espasa: 2695-2786.

Moliner, M. (2007). Diccionario de uso del español. 3. a ed. Madrid: Gredos.

Real Academia Española (1973). Esbozo de una nueva gramática de la lengua española. Madrid: Espasa Calpe [Cit. como Esbozo].

Real Academia Española (2005). Diccionario panhispánico de dudas. Madrid:

Santillana [Cit. como DPD; también en http://rae.es/recursos/diccionarios/ dpd].

Real Academia Española (2006). Diccionario esencial de la lengua española. Madrid: Espasa [también en http://rae.es/recursos/diccionarios/desen].

24. De gran ayuda, en este aspecto, fue la asignatura de Gramática Normativa impartida por Paloma Cuesta en la UNED - la idea de realizar este ejercicio surgió, de hecho, a partir de una actividad propuesta por ella—. 
Real Academia Española (2009). Nueva gramática de la lengua española, 2 vols. Madrid: Espasa [Cit. como NGLE; también en http://rae.es/recursos/ gramatica/nueva-gramatica].

Real Academia Española (2010). Ortografía de la lengua española. Madrid: Espasa [También en http://rae.es/recursos/ortografia/ortografia-2010].

Real Academia Española (2014). Diccionario de la lengua española. 23. a ed. Madrid: Espasa [Cit. como DLE; también en http://rae.es/recursos/diccionarios/drae].

Real Academia Española: Banco de datos (CORDE) [en línea]. Corpus Diacrónico del Español [http://web.frl.es/CORPES/view/inicioExterno.view;j sessionid=793755B4CAAC56A6EF8DEC9FB8CB9C3D].

Real Academia Española: Banco de datos (CORPES XXI) [en línea]. Corpus del Español del Siglo XXI [http://web.frl.es/CORPES/view/inicioExterno.view].

Real Academia Española: Banco de datos (CREA) [en línea]. Corpus de Referencia del Español Actual [http://corpus.rae.es/creanet.html].

Real Academia Española: Nuevo tesoro lexicográfico de la lengua española [http://ntlle.rae.es/ntlle/SrvltGUILoginNtlle; Cit. como NTLLE].

Schachter, J. (1974). «An error in error analysis». Language Learning, Michigan, University of Michigan, 24, vol. 2: 205-214.

Seco, M. (1998). Diccionario de dudas y dificultades de la lengua española. 10, ${ }^{\mathrm{a}} \mathrm{ed}$. Madrid: Espasa.

Seco, M. (2011). Nuevo diccionario de dudas y dificultades de la lengua española. 11. a ed. Madrid: Espasa.

Seco, M. et alii. (1999). Diccionario del español actual. 1. a ed. Madrid: Aguilar. Seco, M. et alii. (2011). Diccionario del español actual. 2.a ed. Madrid: Aguilar. VanPatten, B. (2002). From Input to Output. A Teacher's Guide to Second Language Acquisition. Nueva York: McGraw Hill. 